wish to do so. As such this book can be recommended without qualification. ANDREW Travers

\section{Elihu Thomson}

Selections from the Scientific Correspondence of Elihu Thomson. Edited by Harold J. Abrahams and Marion B. Savin. Pp. xiv +569 . (MIT Press: Cambridge, Massachusetts, and London, 1971.) $\$ 17.50$.

THIs book contains a remarkable collection of letters written and received by an American engineer and scientist of great distinction. Elihu Thomson died in 1937 at the age of 84 , and during his lifetime made a major contribution to the science and practical application of electricity as well as to a lesser though significant effect in other fields as evidenced in his patents numbering over 700. During his early years he formed a close friendship with a teaching colleague, Edward Houston, an association which later developed into the world-famous electrical concern, the Thomson-Houston Company.

The greater part of the correspondence is of course devoted to scientific work, and rarely has a man based his whole life philosophy more on the Latin motto "Rerum cognoscere causas". On January 29,1930 , in a dramatic reply to a former student requesting information on the history of his discovery of the Maxwellian wave, he recounts in a letter of a length equivalent to about three columns of The Times how, at the age of 22 , "for the first time in the world's history that one circuit was tuned to correspond in its constants with another by making the minute changes in its capacity by hanging bits of foil on a wire". He admits that Houston was with him in these experiments, but says, "I do say the ideas were mine." In any case when he raced to the top of the building to find the waves had travelled a hundred feet Houston was not there, "he weighed 186 pounds stripped". The outcome of all these exciting events was of course that Elihu Thomson in 1875 anticipated Marconi by three years in the production of electro-magnetic waves.

An impressive side of Elihu Thomson's character emerges from the wide variety of subjects in which he took a keen interest and carried out pioneer work. From the correspondence between 1899 and 1916 with Hewitt, a distinguished architect and gifted amateur astronomer, and a longer one of 46 letters between 1902 and 1935 with Hale, the one-time Director of the Mount Wilson observatory, it is evident that the production of special glass and of large mirrors of fused quartz occupied much of his time. The step-by- step progress of the work at Lynn makes a sensational story but one which seems, however, to have come to an end with the courageous prediction of a mirror 200 inches in diameter, 30 inches thick and weighing between 25 and 30 tons!

In the longest of the series covered by this book, sixty letters in all, Elihu Thomson and his favourite pen-friend Crompton had much in common. First of all they shared a keen sense of humour: Elihu's specific treatment against influenza was " . . . to get into contact with it as often as possible . . . an attack limits itself by immunity ... if another attack can be obtained at the earliest possible time it will be but a light one". Crompton's ideas on health were rather different: "My invention is to apply radiant heat on the front side of the leg up to the knee. I find that keeping the head cool one does far better brain work." And in his last letter on December 11, 1935, he finds in his 91 st year that, though his memory is to some extent reduced, his mental faculties are not much impaired.

One of the striking aspects of this collection of letters is the number of instances which anticipate future significant developments in science and invention. Throughout the correspondence much light is thrown on the personal character of Elihu Thomson which appears in so many of his letters and can be confirmed by me when I had the pleasure of meeting him in his laboratories at Lynn, Massachusetts, in 1926. He was a lovable man impressing all by his modesty and by the deep careful thought which he gave to any complex matter before declaring an opinion. This book is a wonderful tribute to a great man. Percy Dunsheath

\section{Schneirla's Ants}

Army Ants: A Study in Social Organization. By T. C. Schneirla. Edited by $H$. R. Topoff. Pp. $x x+349+8$ plates. (W. H. Freeman: San Francisco, 1971.) $\$ 12$

THE nomadic Dorylines have become widely known, from works of fiction, as invading armies of ants destroying everything in their path. In fact each colony of African driver ants (Anomma wilverthi) has been estimated to consist of more than $10,000,000$ ants, but their destructive powers have frequently been exaggerated. Eciton colonies, normally numbering at least $1,000,000$ ants, fail to take half of the potential victims in the area raided and active vertebrates usually escape.

At the time of his death in 1968 Schneirla had been studying these phenomenal insects for nearly 40 years and eleven chapters of this book had already been written by him, leaving three to be completed by Topoff. As expected from the author's justly famous earlier publications the central theme of the book is the control of cyclic periods of activity especially in genus Eciton. Each colony normally has one queen which lays eggs in batches separated by a month without laying and the colony is not nomadic while the queen's gaster is swollen with eggs. While each batch of larvae is growing the colony moves each night, but forms temporary "bivouac" nest sites each day and the queen is fully mobile with a reduced gaster. When the larvae cease growing and spin cocoons the colony ceases to be nomadic, the food intake is switched to the queen and the cycle starts again. Schneirla concludes that the cycle is brood determined and each nomadic phase is initiated by the hatching of a new batch of callow workers.

As well as the detailed account of Eciton cycles there is a chapter on colony division and much interesting comparison with other Dorylines, especially the much simpler Aenictus.

Unfortunately the book has faults which reduce its readability. Repetition of information and ideas soon becomes irritating and it was also unnecessary to repeat the colour illustrations in black-and-white or to repeat quotations such as that from Belt appearing on pages 7 and 43. Although the style is claimed to be semipopular it resembles that of scientific papers and in the later chapters there is a fashionable but deplorable tendency to state the obvious in complicated language. The space could better have been used to compare Dorylines with other ants as it is possible for readers to assume that some of the features described are special to Dorylines when they are actually more widespread.

One of the main impressions left on the reader is the high proportion of untested hypotheses presented and it would be appropriate if this book stimulated further field experiments on these fascinating ants-an approach particularly advocated by Schneirla.

\section{A. J. Pontin}

\section{Dating Samples}

Dating Techniques for the Archeologist. Edited by Henry N. Micheal and Elizabeth K. Ralph. Pp. xi 227. (MIT: Cambridge, Massachusetts, and London, November 1971.) \$12.50.

AcCORDING to the blurb, this book has been written on the premise that many archaeologists need to be better informed on modern methods of dating, and it attempts to remedy this situation by discussing the technicalities of the various methods so that the archaeologist will 